\title{
CONGRESOS Y EVENTOS
}

\section{EVENTOS INTERNACIONALES EN ENDOCRINOLOGÍA}

- 12th Annual Word Congress on Insulin Resistance, Diabetes \& Cardiovascular Disease (WCIRDC). 30 de Octubre a 01 de Noviembre de 2014. Los Ángeles, California, Estados Unidos.

- ENDO 2015 - The Endocrine Society's 97th Annual Meeting \& Expo. 05 al 08 de Marzo de 2015. San Diego, California, Estados Unidos.

- AACE 2015 - 24th Annual Scientific \& Clinical Congress. 13 al 17 de Mayo de 2015. Nashville, Tennessee, Estados Unidos.

- 17th European Congress of Endocrinology. 16 al 20 de Mayo de 2015. Dublín, Irlanda.

- ADA 2015 - 75th Scientific Sessions American Diabetes Association. 05 al 09 de Junio de 2015. Boston, Massachusetts, Estados Unidos.

- American Association of Clinical Endocrinologists Advances in the Medical and surgical Management of Thyroid Cancer. 23 y 24 de Junio de 2015. Tampa, Florida, Estados Unidos.

- 51st EASD Annual Meeting, European Association for the Study of Diabetes. 14 al 18 de Septiembre de 2015. Estocolmo, Suecia.

- 15th International Thyroid Congress (ITC hosted by the American Thyroid Association). 18 al 23 de Octubre de 2015. Orlando, Florida, Estado Unidos.

\section{Congreso Colombiano de la Controversia al Consenso}

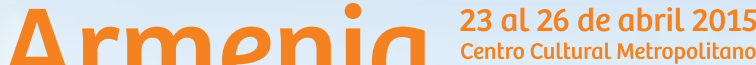 de Conuenciones del 2 uindí}
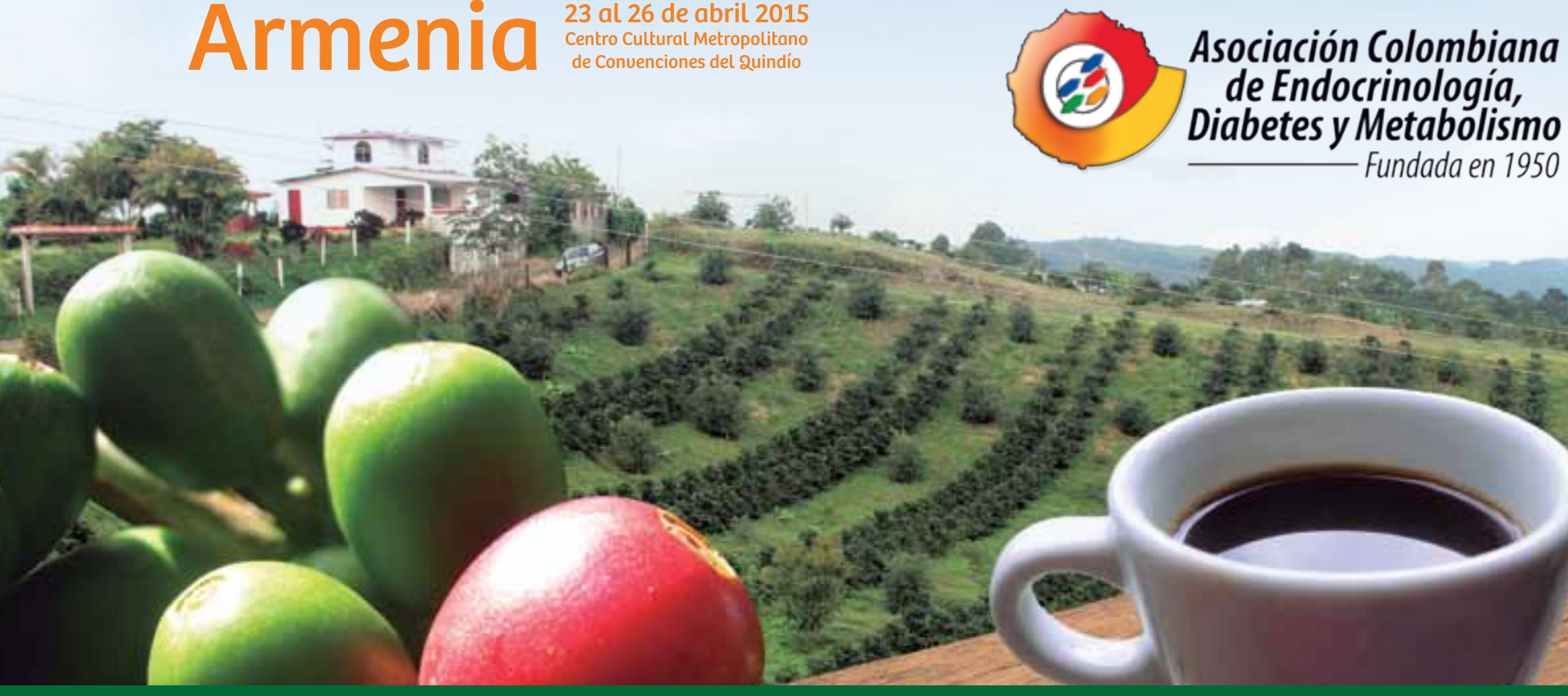

$w \quad w \quad w$ 